Journal of Advanced Research in Fluid Mechanics and Thermal Sciences

\title{
Experimental Analysis of The Effect of Hydrophobic Coating on Pressure Drop in Small Pipes
}

\author{
Michael J Knights ${ }^{1}$, Roy Donald ${ }^{2}$, Diego Galletta ${ }^{3}$, Pun Kul ${ }^{1}$, Faik A Hamad ${ }^{1}{ }^{*}$ \\ School of Science, Engineering and Design, Teesside University Middlesbrough, United Kingdom \\ Nifco UK Ltd Durham Lane, Stockton on Tees, TS16 OPS, United Kingdom \\ Deep Ocean Group, Coniscliffe House 9, Coniscliffe Rd, Darlington DL3 7EE1, United Kingdom
}

\section{ARTICLE INFO}

\section{Article history:}

Received 28 March 2020

Received in revised form 7 July 2020

Accepted 7 July 2020

Available online 29 October 2020

\section{Keywords:}

small pipes; hydrophobic coating;

laminar flow; turbulent flow; pressure

drop

\section{ABSTRACT}

In this paper, experimental results are reported to quantify the effect of hydrophobic coating LT-8 on frictional drag of water flow in pipes of $450 \mathrm{~mm}$ length. Five pipes of 1 , $2,3,4$, and $5 \mathrm{~mm}$ inner diameter were tested. The results from 1,2 and $3 \mathrm{~mm}$ diameter pipes demonstrated an average frictional drag reduction of $9 \%, 11.5 \%$ and $3 \%$, respectively, while the results from $4 \mathrm{~mm}$ and $5 \mathrm{~mm}$ pipes showed an increase in frictional drag of $12 \%$ and $10 \%$, respectively. The $2 \mathrm{~mm}$ and $4 \mathrm{~mm}$ pipes were also tested with a half application of hydrophobic coating. The half coated $2 \mathrm{~mm}$ pipe showed decrease in drag while $4 \mathrm{~mm}$ pipe showed increase in drag. The results indicate a relationship between drag reduction/ increase within the percentage of coated surface. The main conclusions are, the flow changed from laminar state to the liquidair wetting surface condition (Cassie-Baxter wetting state) at the pipe surface and then destabilized by the turbulent boundary layer and entered the liquid wetting surface (Wenzel wetting state) will be appeared. This transition lead to a reduction in friction drag for laminar flow condition and increase in drag for turbulent flow condition.

\section{Introduction}

Hydrophobic surfaces available naturally and their benefits have been recognised for a significant length of time. For example, the Stenocara beetle from Africa's Namib Desert, utilises hydrophilic ridges and hydrophobic troughs on its exoskeleton to channel water towards its head for hydration. The leaves of the lotus flower are also able to remove the possibility of becoming waterlogged in a swamp like environment. This has the added benefit that water rolling off the leaves collects debris, hence cleaning the leaves [1].

\footnotetext{
* Corresponding author.

E-mail address:f.hamad@tees.ac.uk

https://doi.org/10.37934/arfmts.77.1.2435
} 
The existence of slip condition at the wall, and hence the existence of drag reduction, depends on the type of flow examined. Slip velocity has been reported in both laminar [2] and turbulent flow [3]. Fukuda et al., [3] investigated the flow mechanisms which can reduce drag on a horizontal flat plate under specific circumstances, such as the air layers, the addition of surface ridges or riblets etc. They observed the appearance of slip velocity at the wall which leads to drag reduction. Lee et al., [4] studied the effect of surface topology and void fraction on drag reduction in detail. They found that, at low void fractions, the micro-posts outperform the micro-ridges for the same void fraction value of shear-free area. They also found that the slip length increases linearly with void fraction but increased dramatically with the gas fraction higher than $90 \%$.

$\mathrm{Ou}$ and Rothstein [2] studied flow of water in a rectangular channels of $50 \mathrm{~mm}$ length with different cross-sectional dimensions in the range of $76 \times 1520 \mu \mathrm{m}$ to $254 \times 5080 \mu \mathrm{m}$. They observed a slip velocity of more than $60 \%$ of the average velocity in the microchannel is found at the centre of the shear-free air-water interface whereas the no-slip boundary condition is found to hold along the surface of the hydrophobic ridges. Watanabe et al., [5] studied experimentally the change in drag for tap water flowing in a $16 \mathrm{~mm}$-diameter pipe under laminar flow condition. Experiments were carried out to measure the pressure drop and the velocity profile of tap water and an aqueous solution of glycerine flowing in pipes with highly water-repellent walls, by using a pressure transducer and a hotfilm anemometer. They found that the main reason for the fluid slip is the reduction in the molecular attraction between the liquid and the solid surface due to the low free surface energy of the solid. The low free surface energy was attributed to lower contact area of the liquid compared to a conventional smooth surface due to the fine grooves on the solid surface. Liquid cannot flow into the fine grooves which filled with owing to surface tension which could lead to drag reduction. The validity of the term slip condition for microchannel was examined further by Tretheway and Meinhart [6] using micron-resolution particle image velocimetry for flow through $30 * 300 \mu \mathrm{m}$ channels of hydrophilic and hydrophobic surfaces. They found that the velocity profiles measured in a hydrophilic glass were consistent to that estimated analytically and the widely accepted non-slip condition. However, a slip velocity of $10 \%$ of the free-stream velocity and the slip length of $1 \mu \mathrm{m}$ was recorded in the channel with a hydrophobic coating. Rothstein et al., [7] carried out a series of experiments to examine the effect of hydrophobic surface topology of laminar drag reduction using photolithography to fabricate silicon wafers topology into precise micro-post or micro-ridge patterns. They observed a significant drag reduction of up to $40 \%$ was slip lengths of $20 \mu \mathrm{m}$ compared to no drag reduction in smooth hydrophobic surfaces. They attributed drag reduction to an air-water interface which forms between the micro-posts and is supported by surface tension. This enables the fluid to flow while maintaining minimum contact with the channel walls, thus providing a shear-free interface.

Rothstein et al., [8] used the pressure drop and particle imaging velocitimeter to study the effect of micro-patterned hydrophobic surfaces in square channel of $25 \mu \mathrm{m}$ height and $60 \mu \mathrm{m}$ on drag reduction in turbulent flow. They reported drag reduction up to $50 \%$ which increased with increasing feature size and spacing on the surface at a given Reynolds number. They also found that drag reduction started where a viscous sublayer thickness matched the height of the surface feature. Rothstein [9] studied the effect of ultra-hydrophobic surfaces on internal and external flows experimentally and numerically. The results showed a drag reduction of up to $75 \%$ for slip length of 120 microns for Reynolds numbers a round 4000 and increase with higher feature spacing. Zhang et al., [10] examined drag reduction by measuring the pressure loss in channel of $450 \mathrm{~mm}$ length with cross-section of $9 \mathrm{~mm}$ width and $1.75 \mathrm{~mm}$ height. They reported drag reduction up to $54 \%$ in laminar and turbulent flow for Reynolds numbers in the range of 500 to 5000 . Rios-Rodriguez et al., [11] investigated the existence slip conditions of laminar flow for Reynolds numbers in the range of 70 - 
250 in circular hydrophobic pipe of $14.1 \mathrm{~mm}$ inner diameter. They reported a $20 \%$ reduction of pressure drop in the coated channel compared to the non-coated ones.

In the literature, most of the papers regarding pressure drop and drag reduction in hydrophobic pipes, are published on rectangular and micro pipes. Only a few, early investigations on pressure drop for laminar flow in hydrophobic pipes in the range of $1-5 \mathrm{~mm}$ pipes [12-15] were documented. Hence, the purpose of this paper is to

i. Study the pressure drop in small pipes with hydrophobic ally coated and non-coated surfaces in the order of millimetres.

ii. Understand the effect of pipe diameter $(1,2,3,4$ and $5 \mathrm{~mm})$ and Reynolds number $(0-$ 10000 ) on the drag increase/reduction of hydrophobic coated surface. iii) Use high speed camera to understand the effect of hydrophobic surface on flow behaviour.

\section{Methodology}

\subsection{Test Rig Manufacture}

In order to achieve a comprehensive overview of pressure drop in small pipes, two experimental rigs were designed and build to examine 5 small pipes of both 1, 2, 3, 4 and $5 \mathrm{~mm}$ inner diameter. Figure 1 shows the test rig for the 2 and $4 \mathrm{~mm}$ inner diameter pipes. A similar experimental rig was also designed and manufactured to examine the pipes of $1 \mathrm{~mm}, 3 \mathrm{~mm}$, and $5 \mathrm{~mm}$ diameter. Each test rig was manufactured from two thick sheets of Perspex $(25 \mathrm{~mm})$ were initially machined flat before machining of the settling chamber. The pipes of $450 \mathrm{~mm}$ length were then created using ball nose cutters of appropriate diameter. Valve holes and assembly holes where then drilled. The CNC machine was used to minimize the error in dimensions and allows for precision features to be machined. The holes were then tapped by hand using tapping tools.

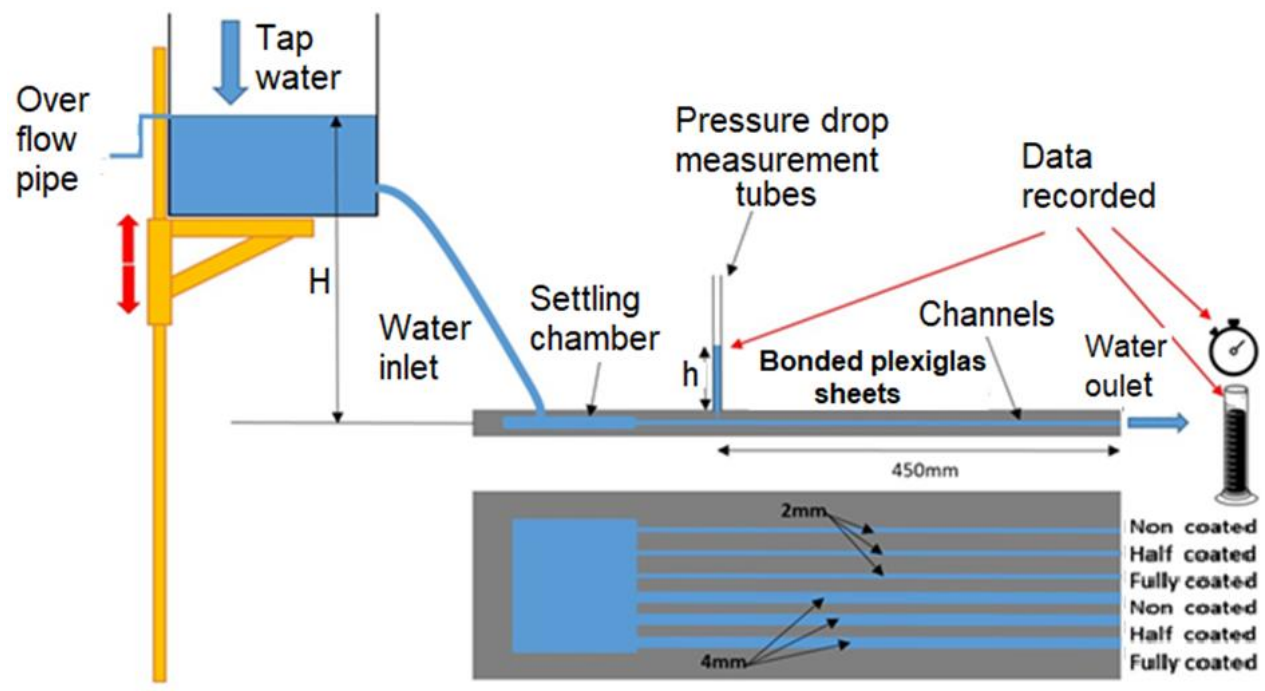

Fig. 1. Schematic diagram of experiment facility

The rig was cleaned before the hydrophobic coating was applied to pipes. The LT- 8 coating is a high performance fluopolymer dissolved in a non-flammable fluorinated solvent. The LT-8 coating exhibits superior hydrophobic (water repellent) and oleophobic (oil repellent) properties at submicron level. The LT8-2 coating can be removed using methyl nonafluorobutyl ether (HFE-7100). The HFE-7100 solution can be applied for I hour to break down the LT8-2 coating before can be removed using clean cotton swabs. To confirm the existence or elimination of the LT8-2 coating, a visual inspection can be performed of the surface contact angle and wettability to observe the effect. The 
thickness of the hydrophobic layer formed on the surface of 2-3 $\mu \mathrm{m}$ which was estimated by microscopic examination. The LT-8 hydrophobic solution.

\subsection{Experimental Procedure}

The test rig was placed on a large table to minimize the difference in level between the inlet and outlet of pipes. However, the distance between the floor and the four corners of the table was measured to confirm the horizontal level. The level of water in the tank kept constant by using a floating ball valve. The water flow rate controlled by a valve system allows flow rate to be controlled in each pipe individually. The flow exiting each pipe will be collected in a graduated cylinder for a specific time to calculate the flow rate. The data will then be used to evaluate the velocity of the flow and then used to calculate the Reynolds number. The values of height from the manometer readings, $h$, will be used to calculate the pressure difference due to friction losses of the flow within each pipe using Eq. (1)

$\mathrm{P}=\rho g h$

The water tank will then be elevated, and the experiment repeated. The change of elevation of the water tank is used to control the flow rate (Reynolds number) in the pipes. The relationship between the pressures in each pipe and Reynolds number will then be graphically presented.

For the pipe of 2 and $4 \mathrm{~mm}$ diameter, data will also be recorded for $1 / 2$ coated pipes. Data will then be compared to that of coated and non-coated pipes. High definition imagery recording will be taken of the flow in each pipe in order to examine the effect of coating on flow properties. The imagery will capture video at a rate or 100 frames per second.

\section{Results and Discussion}

\subsection{Initial Measurement}

The experimental data was collected for non-coated, half-coated and fully coated pipes by varying the height of the tank $(\mathrm{H})$ which gives different flow rates (Reynolds numbers). High speed camera was also used to examine the flow profile in each pipe by monitoring the air bubbles generated from the naturally dissolved air in water. The flows in the non-coated and fully coated pipes showed a symmetrical flow profiles while the half-coated pipe showed asymmetrical flow profile.

The settling chamber prior to the flow was used to make sure that a similar initial condition of the flow for all the pipes is achieved. It is also more easer and cost effective to machine a number of channels in one Perspex sheet than individual channel. To confirm that settling chamber has no effect on pressure drop, the pressure drop was measured for 2 and $4 \mathrm{~mm}$ pipes (non-coated) without settling chamber.

\subsection{Variation of Pressure Drop with Reynolds Number}

For $5 \mathrm{~mm}$ pipe, as can be seen in Figure 2, the coated pipe shows an increase in pressure drop of $10 \%$ when compared to the non-coated pipe. However, the discrepancy is small for $\operatorname{Re}<5000$, but increased with higher Reynolds number. It can be observed that the flow is turbulent for all data points. 


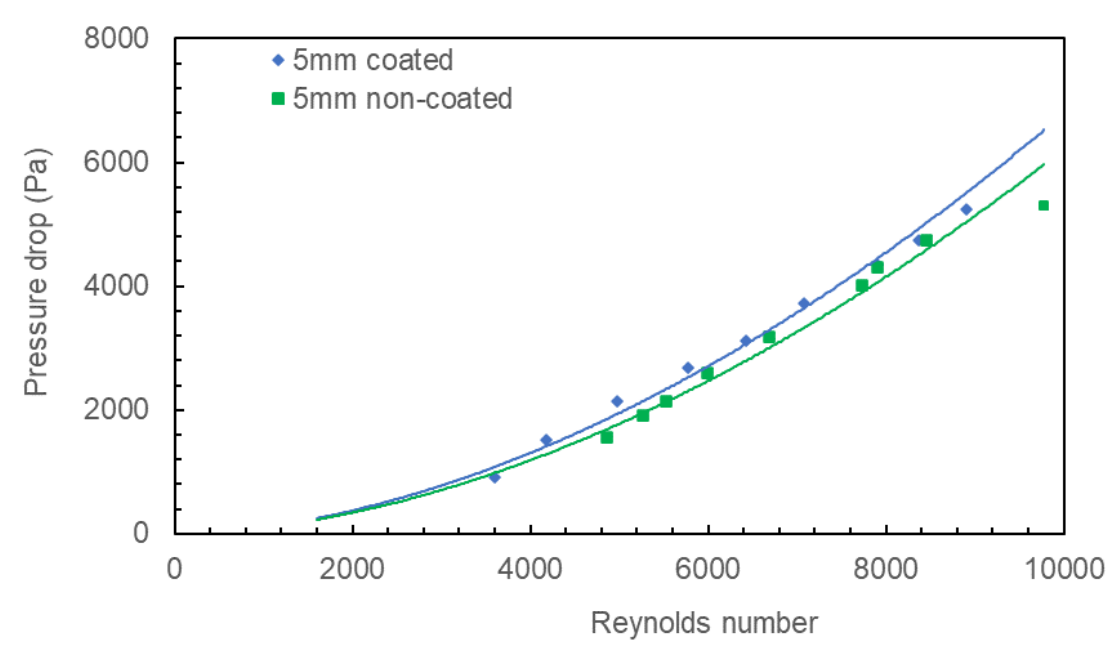

Fig. 2. Comparison of pressure drop between coated and non-coated pipes ( $5 \mathrm{~mm}$ inner diameter pipe)

Figure 3 presents the data for $4 \mathrm{~mm}$ pipe. The results are in the range of transition and turbulent flow regime. It can be observed that the pressure drop for coated pipe is higher by $12 \%$ compared to non-coated pipe. The discrepancy increased for higher Reynolds numbers. The data of pressure drop for coated pipe shows a step increase for $\operatorname{Re}>4170$. This may be attributed to experimental error in measurement of one the variables. The increase in pressure drop for coated pipes of 5 and $4 \mathrm{~mm}$ may attribute to the Wenzel wetting state [18] where the coating reduces the air gaps on the surface and increase the friction losses compared to uncoated surface.

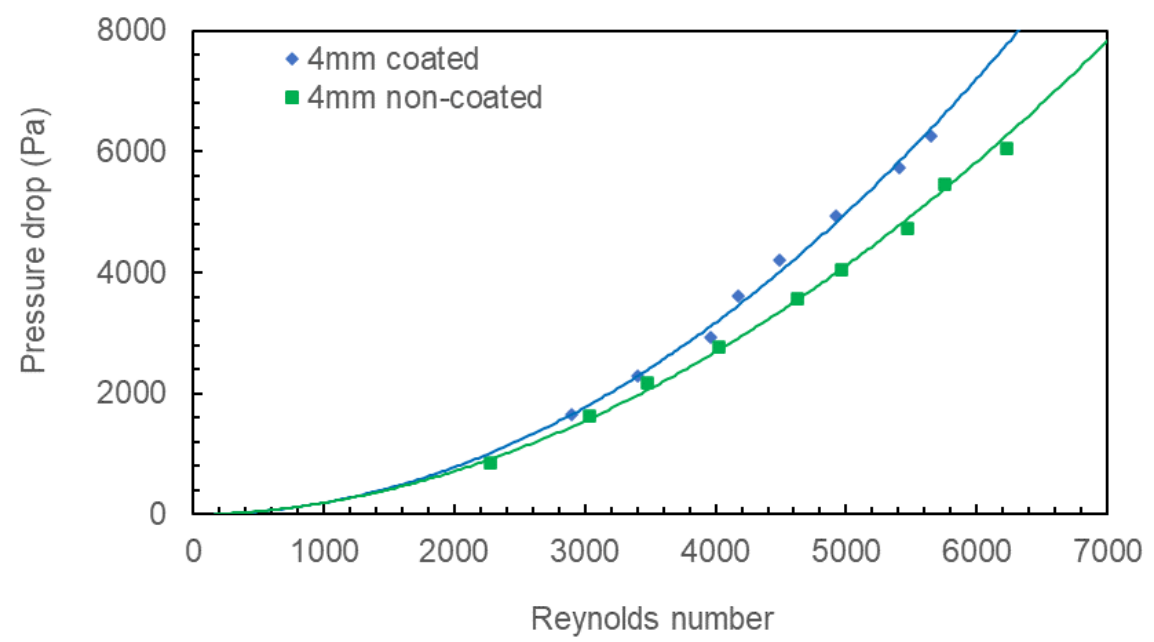

Fig. 3. Comparison of pressure drop between coated and non-coated pipes (4 mm inner diameter pipe)

The results for pressure drop in Figure 4 of coated and non-coated $3 \mathrm{~mm}$ pipes are much closer. The data from coated pipe is $3 \%$ lower than the non-coated pipe. The results from $3 \mathrm{~mm}$ pipe in Figure 4 provides an interesting transition between the flow in pipes of 4 and $5 \mathrm{~mm}$ compared to flow in pipes 1 and $2 \mathrm{~mm}$. The $3 \mathrm{~mm}$ diameter can be considered as the boundary between the pipes that considered as small and the conventional pipes. This change in trend of drag reduction may be attributed to the increased effect of viscosity on the flow at the central zone of the small pipes compared to the large pipes. This finding is supported by the value of $3 \mathrm{~mm}$ for multiphase flow transition suggested by [16]. 


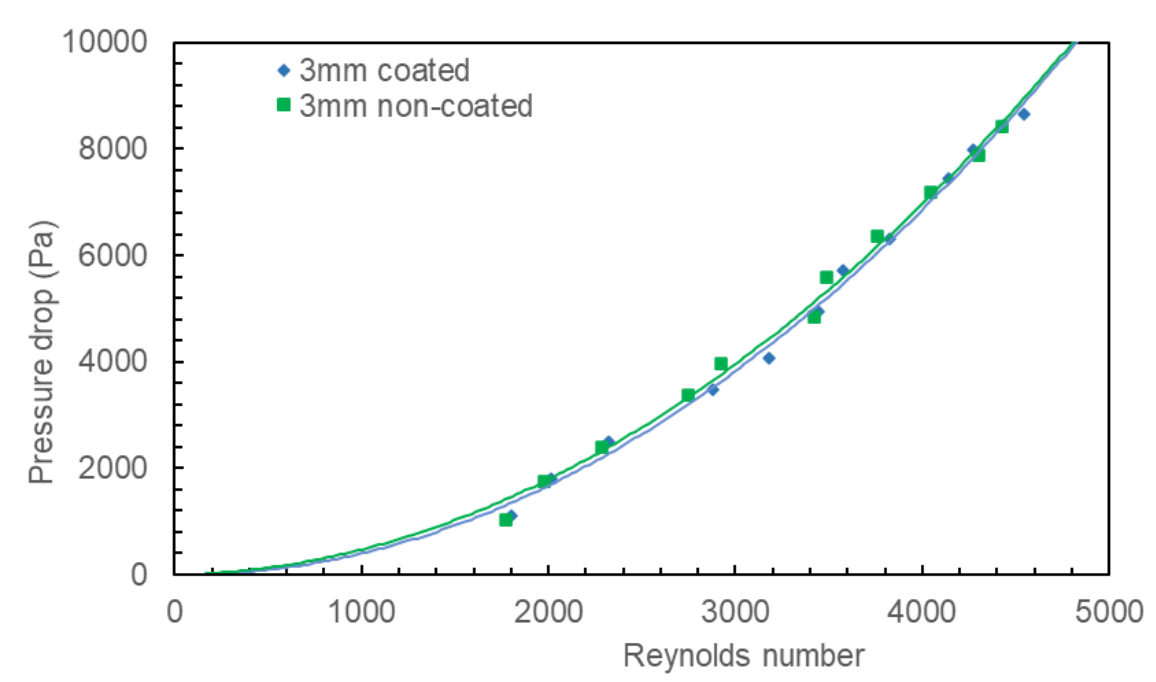

Fig. 4. Comparison of pressure drop between coated and non-coated pipes ( $3 \mathrm{~mm}$ inner diameter pipe)

In Figure 5, the results for flow in $2 \mathrm{~mm}$ pipe indicates pressure reduction due to the applied hydrophobic coating of $11.5 \%$. This is in agreement with the work conducted by [5, 10 and 11$]$. It should be highlighted that all data points of the $2 \mathrm{~mm}$ pipe were within the laminar flow regime. The only exception is the point with highest Reynolds number value which have passed into the transition flow regime.

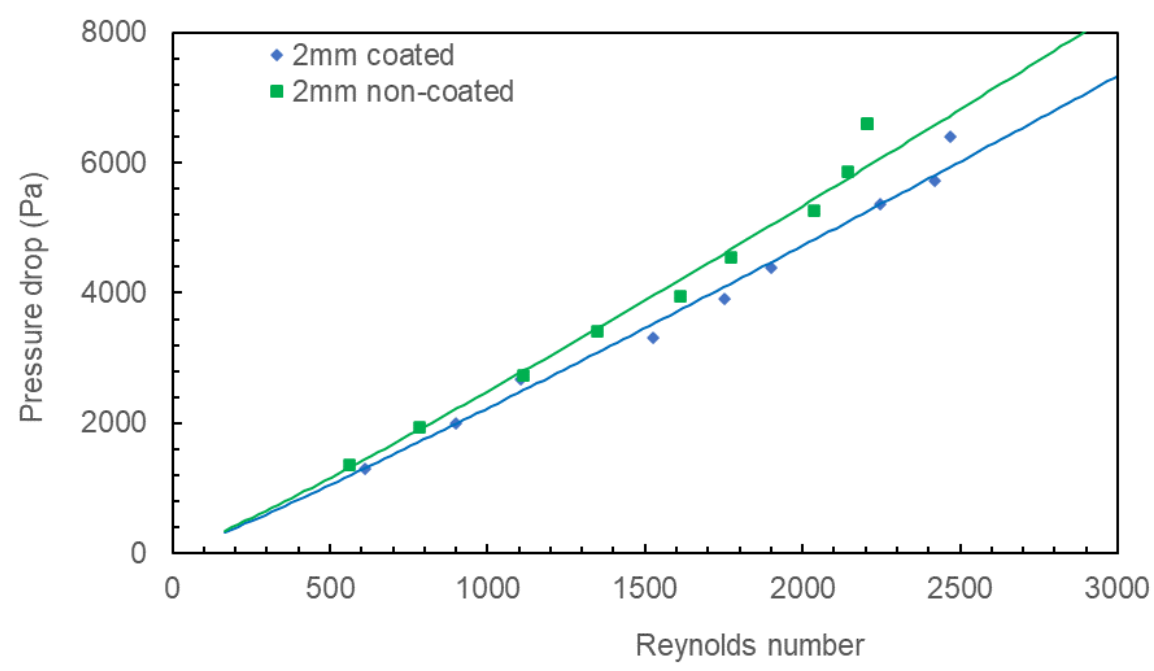

Fig. 5. Comparison of pressure drop between coated and non-coated pipes ( $2 \mathrm{~mm}$ inner diameter pipe)

The results of the $1 \mathrm{~mm}$ pipe experiment, as seen in Figure 6, reveal a comparable relationship to that of the $2 \mathrm{~mm}$ pipe. Thus, for laminar flow regimes in small pipes the apparent drag reducing effect of hydrophobic coating appears confirmed. The correlation between pressure and Reynolds number is clearly linear. An average drag reduction of $9 \%$ has been recorded. 


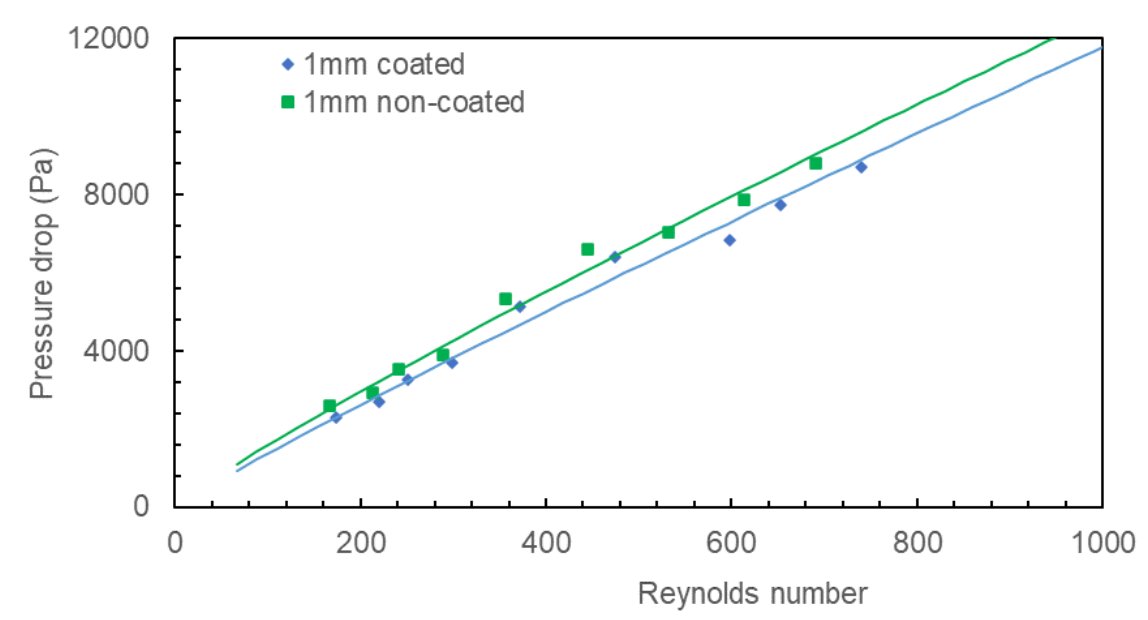

Fig. 6. Comparison of pressure drop between coated and non-coated pipes (1 $\mathrm{mm}$ inner diameter pipe)

In summary, the present data for laminar flow in the 1,2 and $3 \mathrm{~mm}$ pipes show a reduction pressure drop for coated pipes which is support by a similar finding from the literature [2], [5], [11] and [17]. The main reason for this behaviour was attributed to the slip condition at wall due to the liquid-air wetting surface condition (Cassie-Baxter wetting state) at the pipe surface.

On other hand, the present data for transition and turbulent flow are in contradiction with the finding in the literature given by [9] and [10]. This may attribute the difference surface topography [7] between present work and data from literature. This means that the size and spaces of ridges and troughs are the controlling factor of drag increase/reduction by controlling the actual contact surface area between the liquid and the pipe surface and how much void trapped in the troughs. Based on the surface characteristics reported in [7], the increase in pressure drop in present work can be attributed to the reduction in voids at the wall and increase of direct contact between water and the pipe wall in turbulent flow regime.

\subsection{Variation of Pressure Drop with Percentage of Coated Pipe Wall}

Two cases for $2 \mathrm{~mm}$ and $4 \mathrm{~mm}$ pipes are investigated for $0,50 \%$ and $100 \%$ coating. The $2 \mathrm{~mm}$ can be considered as small pipe and $4 \mathrm{~mm}$ as conventional pipe. The examination of half coated $4 \mathrm{~mm}$ pipe seen in Figure 7 portrays more than $50 \%$ of pressure increase of the fully coated as the trend line is closer to fully coated pipe than non-coated. This is likely due to the effect of pipe wall surface the change in flow structure due to asymmetrical flow condition in the half-coated pipe as shown by images. All of the data points are within the transitional and turbulent flow regimes. The increase in pressure drop may be attributed to the combined effect of reducing the size of air gaps on the surface by coating and removing the air from the gaps by the turbulence eddies which lead to direct contact between the water and pipe wall. This condition will create Wenzel wetting state which increase friction losses in coated pipe compared to uncoated pipe.

The $2 \mathrm{~mm}$ pipe results, seen in Figure 8 , show a strong similarity to that of the $4 \mathrm{~mm}$ pipe with the half-coated data points being located between the coated and non-coated pipes. However, the data of half-coated pipe are very close to non-coated pipe compared to that of the coated pipe. This is in contrast to that observed for the turbulent in $4 \mathrm{~mm}$ pipe. In this case, the asymmetry effect is more significant than the percentage of coated pipe surface. 


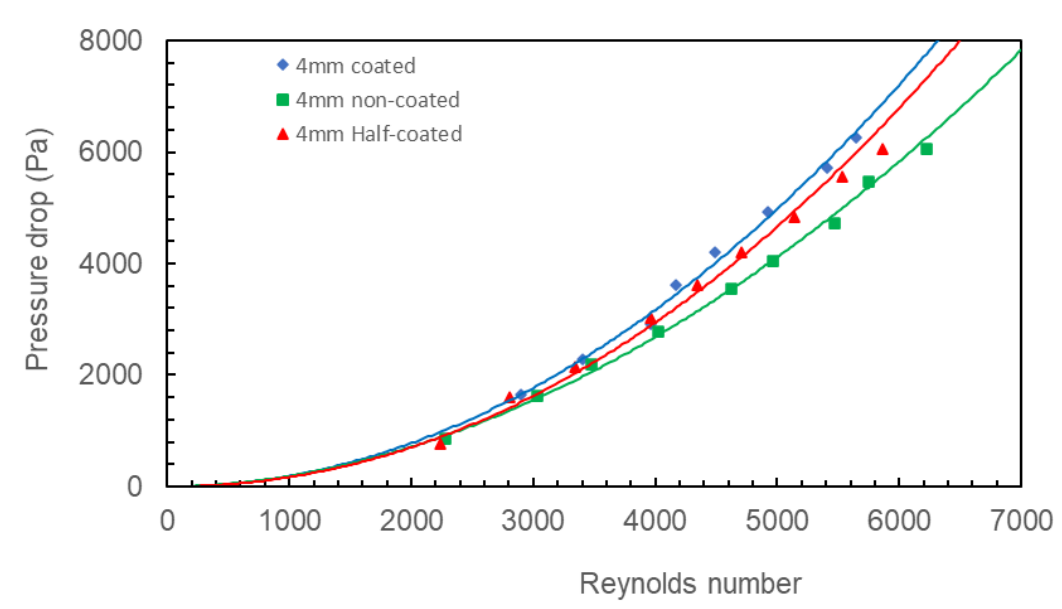

Fig. 7. The pressure drop of coated, $1 / 2$ coated and non-coated pipes (4 mm pipe)

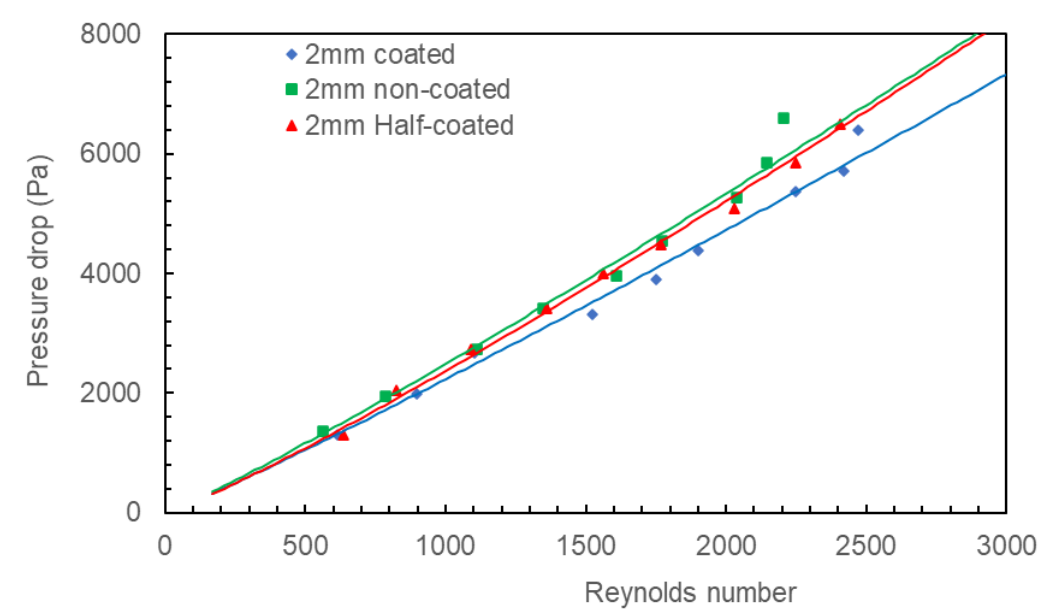

Fig. 8. The pressure drop of coated, $1 / 2$ coated and non-coated pipes ( $2 \mathrm{~mm}$ pipe)

\subsection{Comparison of Pressure Drop for Flow from Settling Chamber and Without Settling Chamber}

To confirm that settling chamber has no effect on the measurement of pressure drop, the data collected from 2 and $4 \mathrm{~mm}$ pipes (non-coated) with and without settling chamber. Figure 9 present the data of pressure drop collected from the experiments. The results confirm that there is no effect of using settling chamber on pressure measurements.

Figure 10 present a summary of the results from all coated and non-coated pipes. The results offer an increased perspective and quantification of drag variations in hydrophobic small pipes. When the results are graphically inspected together, a common trend of the effect of coating on pressure drop is recognised. As the Reynolds number increases past values of laminar flow seen in the 1 and $2 \mathrm{~mm}$ pipes, Cassie Baxter air trapping reduces drag allowing the flow to enter the transition/ turbulent flow regime which in turn creates a Wenzel wetting state leading to a drag increase. 


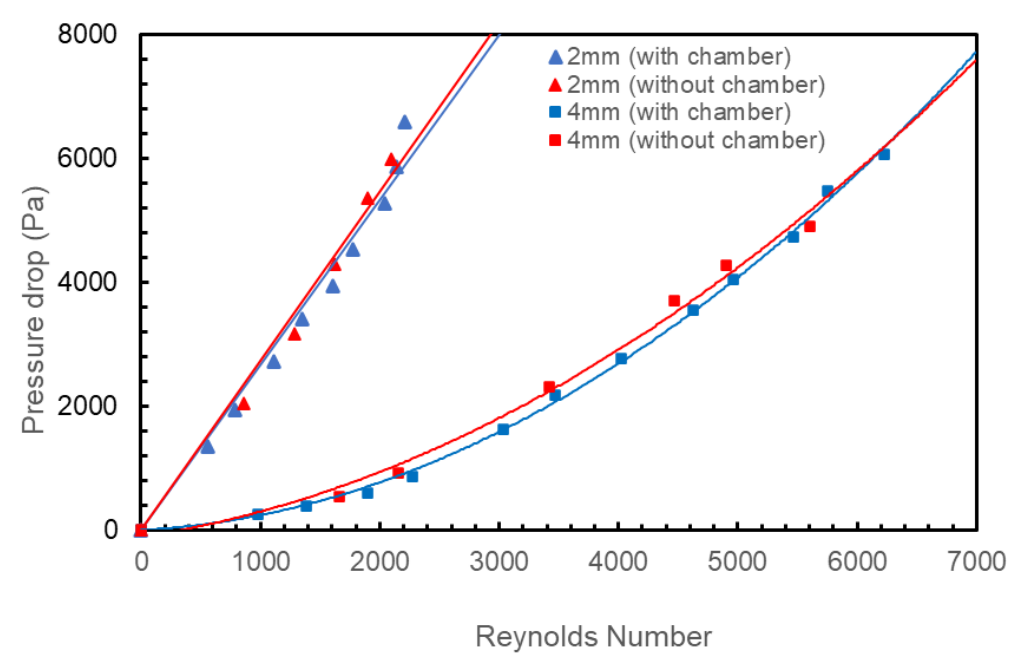

Fig. 9. Comparison of pressure drop for flow with and without settling chamber ( 2 and $4 \mathrm{~mm}$ pipes)

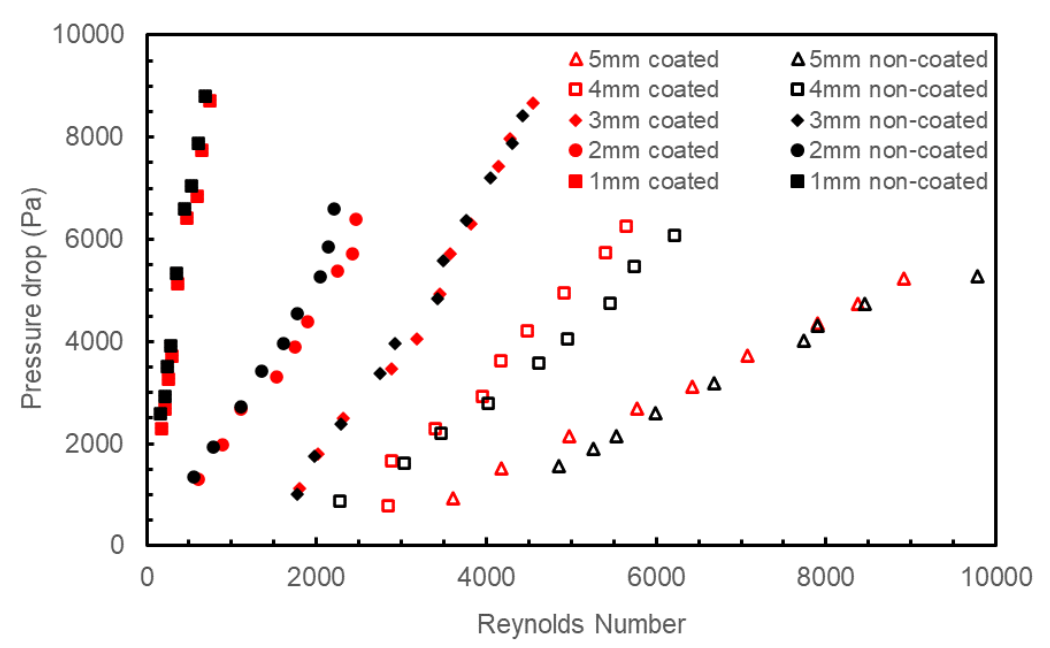

Fig. 10. Comparison of the results from all pipes (coated and noncoated)

\subsection{High Definition Imagery Results}

In attempts to understand the effect of the pipe surface topology on flow behaviour, a high speed camera is used to record videos of the flows from each pipe used in the investigation. The detailed examination of these videos show small bubbles appeared in the flow. The source of these bubbles could be the dissolved air in water. The data are collected for same pipe diameter $(2 \mathrm{~mm})$ and similar Reynolds numbers (3150) to create a similar flow conditions. we recorded a lot of videos to find this case of similar flow conditions and the bubble appear naturally from dissolved air in the water.

High definition recordings of the flow within each pipe were taken and then analysed, with particular attention paid to the shape and trajectory of bubbles. Figure 11 presents the typical flow trajectory recognised throughout the fully coated and non-coated pipes. The bubble can be seen to follow a trajectory parallel to the pipe axis with negligible deflection from this path. The bubble path is almost a straight line for laminar and turbulent flow. 


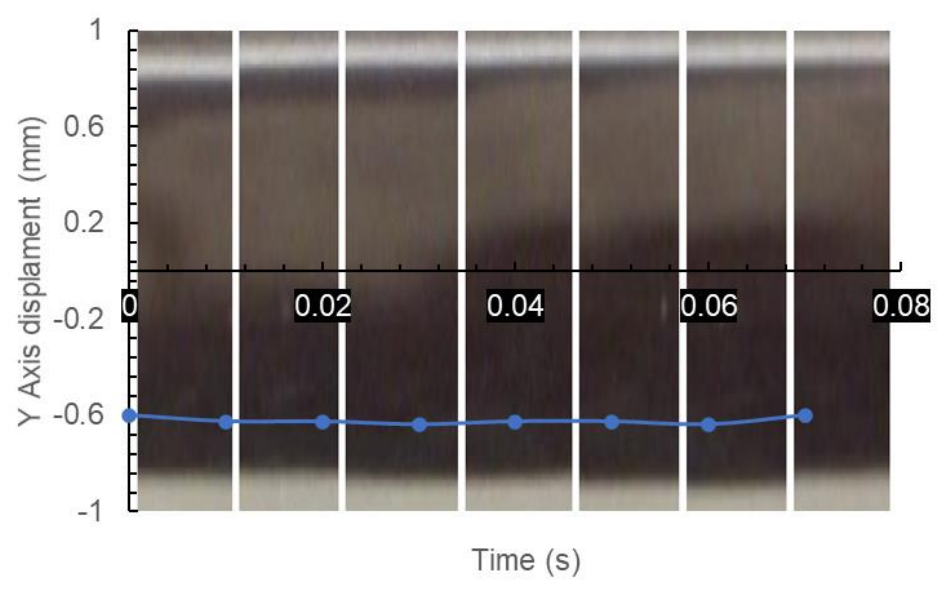

Fig. 11. Bubble trajectory in $2 \mathrm{~mm}$ pipe in relation to Y-Axis in coated pipe $(\operatorname{Re} \approx 3150)$

Figure 12 presents the trajectory of bubble in $2 \mathrm{~mm}$ half-coated pipe. The bubbles appear to oscillate about the axis of the pipe in y direction. This was recognised in all half-coated pipes, and each bubble followed a similar trajectory in Figure 12. This shows that the difference in flow interaction with the two half of the pipe wall are creating a non-equilibrium condition which lead to the oscillation of the bubbles around the axis of the pipe. The unbalanced forces on the bubble may lead to a continuous rotation and generation of vortices in flow in the pipe.

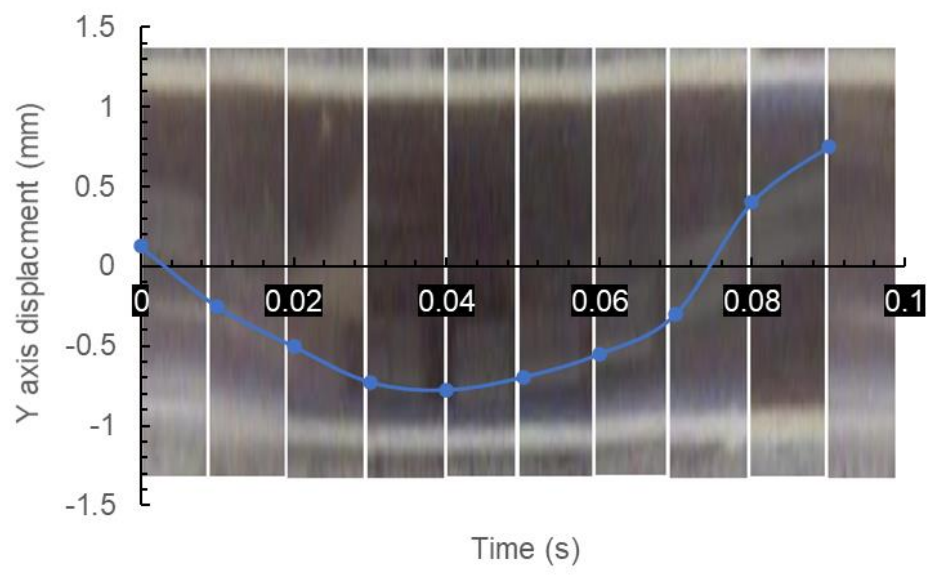

Fig. 12. Bubble trajectory $2 \mathrm{~mm}$ pipe in relation to $\mathrm{Y}$-Axis in half coated pipe $(\operatorname{Re} \approx 3150)$

Figure 13 presents the variation of average bubble size with pipe diameter. The size and shape of the bubbles in each flow is differed but appeared to present a trend. The $3 \mathrm{~mm}$ diameter pipe is not included in this Figure 13 due to the difficulty of observing any bubbles in the recorded images. The average bubble size of the bubbles appears to decrease as the pipe diameter increases. Elongation of the bubbles within turbulent flows was also recognised. Multiple measurements of bubble dimensions were taken for each bubble and then averaged to give an average bubble size. The decrease in bubble size may be attributed to the increase in turbulence experienced by the flow in the larger diameter pipes and further experimentation is required to confirm that the turbulence is the only reason for this trend. 


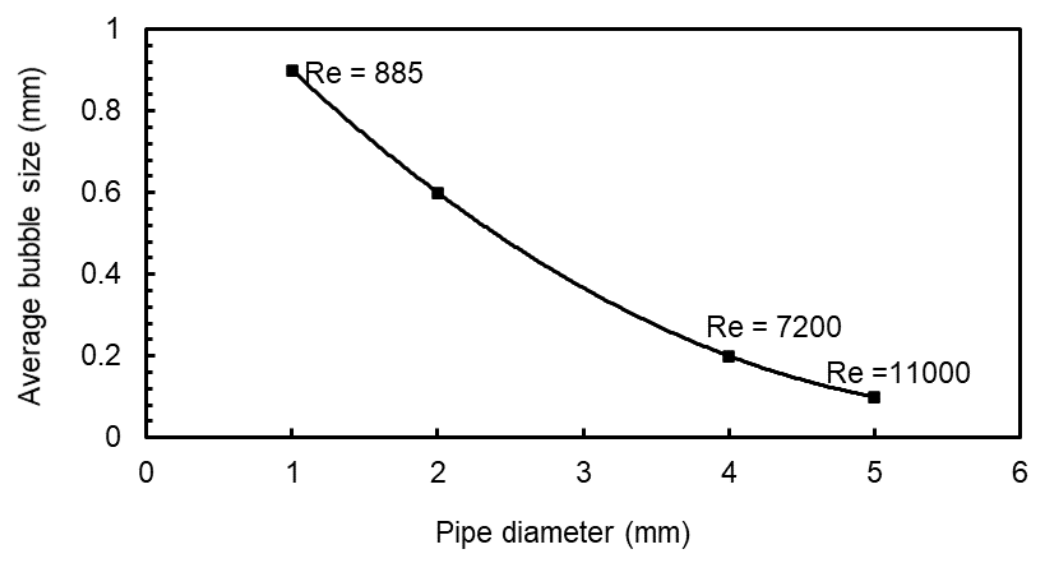

Fig. 13. Variation of average bubble diameter with to pipe diameter

\section{Conclusions}

The experimental data provided a comprehensive overview of pressure drop in small pipes with $0,50 \%$ and $100 \%$ hydrophobic coating of inner pipe surface over the Reynolds range from 150 to 10000. The main findings can be summarized as

i. The hydrophobic coating reduces the drag for laminar flow in small pipes of 1 and $2 \mathrm{~mm}$ by around $10 \%$ but increase the drag by around $10 \%$ in transition and turbulent flow in the larger pipes of 4 and $5 \mathrm{~mm}$. This behaviour may attributed to the change from the liquid-air wetting surface condition to the liquid wetting surface of the pipes used in this paper.

ii. The increase of drag in transition and turbulent flow may be attributed to the very smooth surfaces of the pipes used in present work. This minimized/ eliminated any slip velocity at the wall which depend on the surface topology.

iii. There is a correlation between the percentage of surface coating and the drag reduction/increase. This correlation is not linear due the additional effect from the possible generation of vortices in the flow due to unbalanced shear forces on the walls.

iv. The data from $3 \mathrm{~mm}$ pipe indicating a transition from small pipes where the viscosity have a significant influence on the velocity profiles to large pipes when momentum have more influence on velocity profiles.

v. The high definition imagery has presented some interesting and intriguing information, in particular on the half-coated bubble trajectories. The complex interactions between fully coated and non-coated pipe walls will be invaluable to industry. The data provided within this article will present microfluidics and biometrics with opportunity to maximize the efficiency and reduce maintenance of any system which operated under hydrophobic conditions in small pipes.

\section{References}

[1] Neinhuis, C., and W. Barthlott. "Characterization and distribution of water-repellent, self-cleaning plant surfaces." Annals of botany 79, no. 6 (1997): 667-677. https://doi.org/10.1006/anbo.1997.0400

[2] Ou, Jia, and Jonathan P. Rothstein. "Direct velocity measurements of the flow past drag-reducing ultrahydrophobic surfaces." Physics of fluids 17, no. 10 (2005): 103606. https://doi.org/10.1063/1.2109867

[3] Fukuda, Kazuhiro, Junichiro Tokunaga, Takashi Nobunaga, Tatsuo Nakatani, Toru Iwasaki, and Yoshikuni Kunitake. "Frictional drag reduction with air lubricant over a super-water-repellent surface." Journal of Marine Science and Technology 5, no. 3 (2000): 123-130. https://doi.org/10.1007/s007730070009

[4] Lee, Choongyeop, and Chang-Hwan Choi. "Structured surfaces for a giant liquid slip." Physical review letters 101, no. 6 (2008): 064501. https://doi.org/10.1017/S0022112098003747 
[5] Watanabe, Keizo. "Yanuar, and H. Udagawa." J. Fluid Mech $381 \quad$ (1999): 225. https://doi.org/10.1017/S0022112098003747

[6] Tretheway, Derek C., Luoding Zhu, Linda Petzold, and Carl D. Meinhart. "Examination of the slip boundary condition by $\mu$-PIV and lattice Boltzmann simulations." In ASME International Mechanical Engineering Congress and Exposition, vol. 36487 (2002): 551-556. https://doi.org/10.1063/1.1432696

[7] Ou, J. BP and JP Rothstein."Laminar Drag Reduction in Microchannels Using Ultrahydrophobic Surfaces.". Physics of Fluids 16 (2004): 4635-4643. https://doi.org/10.1063/1.1812011

[8] Daniello, Robert J., Nicholas E. Waterhouse, and Jonathan P. Rothstein. "Drag reduction in turbulent flows over superhydrophobic surfaces." Physics of Fluids 21, no. 8 (2009): 085103. https://doi.org/10.1063/1.3207885

[9] Rothstein, Jonathan P. Turbulent drag reduction using micro and nanotextured ultrahydrophobic surfaces. MASSACHUSETTS UNIV AMHERST, 2010. https://doi.org/10.21236/ADA513497

[10] Zhang, J., Z. Yao, P. Hao, H. Tian, and N. Jiang. "Fluid drag reducing effect and mechanism of superhydrophobic surface with micro-nano textures." In 4th Micro and Nano Flows Conference, (2014): 7-10.

[11] Ríos-Rodríguez, A., C. A. Palacios-Morales, E. Bernal, G. Ascanio, and J. P. Aguayo-Vallejo. "Effect of Hydrophobic Coating on Hagen-Poiseuille Flows." Journal of Applied Fluid Mechanics 9, no. 3 (2016): $1035-1040$. https://doi.org/10.18869/acadpub.jafm.68.228.24586

[12] Cheng, Lixin, and Dieter Mewes. "Review of two-phase flow and flow boiling of mixtures in small and mini channels." International Journal of Multiphase Flow 32, no. $2 \quad$ (2006): $183-207$. https://doi.org/10.1016/i.ijmultiphaseflow.2005.10.001

[13] Baek, Seungwhan, Sangkwon Jeong, and Gyuwan Hwang. "Pressure drop characteristics of cryogenic mixed refrigerant at macro and micro channel heat exchangers." Cryogenics 52, no. 12 (2012): 689-694. https://doi.org/10.1016/i.cryogenics.2012.06.012

[14] Yang, C. Y., and R. L. Webb. "Friction pressure drop of R-12 in small hydraulic diameter extruded aluminum tubes with and without micro-fins." International Journal of Heat and Mass Transfer 39, no. 4 (1996): 801-809. https://doi.org/10.1016/0017-9310(95)00151-4

[15] Yang, Chien-Yuh. "Friction characteristics of water, R-134a, and air in small tubes." Microscale Thermophysical Engineering 7, no. 4 (2003): 335-348. https://doi.org/10.1080/10893950390243608

[16] Kandlikar, Satish G. "Fundamental issues related to flow boiling in minichannels and microchannels." Experimental Thermal and Fluid Science 26, no. 2-4 (2002): 389-407. https://doi.org/10.1016/S0894-1777(02)00150-4

[17] Watanabe, Keizo, Katsutoshi Ohkido, and Hiroshi Mizunuma. "Drag reduction in flow through square and rectangular ducts with highly water repellent walls." American Society of Mechanical Engineers, Fluids Engineering Division (Publication) FED 237 (1996): 115-119.

[18] Wenzel, Robert N. "Resistance of solid surfaces to wetting by water." Industrial \& Engineering Chemistry 28, no. 8 (1936): 988-994. https://doi.org/10.1021/ie50320a024 